\title{
Os percursos do parto nas políticas de saúde no Brasil por suas testemunhas: entrevista com Maria do Carmo Leal e Marcos Dias
}

\author{
A firsthand description of childbirth's pathways into Brazilian health \\ policies: interview with Maria do Carmo Leal and Marcos Dias
}

Entrevista com

Maria do Carmo Leal

Professora e pesquisadora, Escola Nacional de Saúde Pública Sergio Arouca/Fiocruz.

Rio de Janeiro - RJ - Brasil

orcid.org/0000-0002-3047-515X

duca@ensp.fiocruz.br

Marcos Augusto Bastos Dias

Professor e pesquisador, Instituto Nacional de Saúde da Mulher, da Criança e do Adolescente Fernandes Figueira (IFF)/Fiocruz. Rio de Janeiro - RJ - Brasil orcid.org/0000-0003-1386-7001 marcosad@centroin.com.br

Concedida a

\section{Claudia Bonan}

Professora e pesquisadora, IFF/ Fiocruz.

Rio de Janeiro - RJ - Brasil orcid.org/0000-0001-8695-6828

cbonan@globo.com

\section{Andreza Rodrigues \\ Nakano \\ Professora, Escola de Enfermagem Anna Nery/Universidade Federal do Rio de Janeiro. \\ Rio de Janeiro - RJ - Brasil \\ orcid.org/0000-0002-1873-5828 \\ andrezaenfermeira@gmail.com \\ Luiz Antônio Teixeira \\ Professor e pesquisador, Casa de Oswaldo Cruz/Fiocruz; professor, Universidade Estácio de Sá. Rio de Janeiro - RJ - Brasil orcid.org/0000-0001-8871-0928 luiztei3@gmail.com}

Recebido em 9 fev. 2018. Aprovado em 10 abr. 2018.
BONAN, Claudia; NAKANO, Andreza Rodrigues; TEIXEIRA, Luiz Antônio. Os percursos do parto nas políticas de saúde no Brasil por suas testemunhas: entrevista com Maria do Carmo Leal e Marcos Dias. História, Ciências, Saúde - Manguinhos, Rio de Janeiro, v.26, n.1, jan.-mar. 2019, p.319-334.

\section{Resumo}

A entrevista aborda os percursos que colocaram o parto na pauta das políticas públicas brasileiras. Maria do Carmo Leal e Marcos Dias são participantes ativos nesse percurso, tanto no campo acadêmico como no âmbito do ativismo. Na entrevista, os depoentes refletem sobre os desafios enfrentados para alcançar uma mudança no modelo assistencial brasileiro e destacam a importância da participação das mulheres e de seus movimentos no alcance desse objetivo.

Palavras-chave: Parto; políticas públicas; história; ativismo.

\section{Abstract}

This interview discusses the pathways that brought childbirth into Brazilian public policies. Maria do Carmo Leal and Marcos Dias are active participants in this journey, in academics as well as activism. In the interview, the participants reflect on the challenges to achieving change in the Brazilian health care model and highlight the importance of women's participation and their movements in reaching this goal.

Keywords: Childbirth; public policies; history; activism. 
$\mathrm{A}$ entrevista aborda os percursos que colocaram o parto na pauta das políticas públicas brasileiras. Os entrevistados são participantes ativos nesse percurso, tanto no campo acadêmico como no âmbito do ativismo. Maria do Carmo Leal é médica e pesquisadora titular da Fundação Oswaldo Cruz, onde vem desenvolvendo estudos na área da epidemiologia perinatal. Entre 2009 e 2013 coordenou a pesquisa "Nascer no Brasil: inquérito nacional sobre parto e nascimento", estudo que trouxe novos olhares para a assistência ao parto no país. Os desdobramentos do inquérito e as novas pesquisas sobre o nascer - como a "Nascer nas prisões" - têm, sob a coordenação de Maria do Carmo, apresentado os desafios das políticas públicas no campo do parto e nascimento. Marcos Dias é médico obstetra e pesquisador no Instituto Nacional de Saúde da Mulher, da Criança e do Adolescente Fernandes Figueira. Sua trajetória é marcada pela participação em movimentos de profissionais que questionaram, desde os anos 1980, a forma hegemônica de assistência ao parto. Dias foi diretor de maternidade e coordenou a área de Saúde da Mulher no município do Rio de Janeiro, participando de eventos centrais para a construção de políticas públicas relacionadas ao parto. Na entrevista, os depoentes refletem sobre os desafios enfrentados para alcançar uma mudança no modelo assistencial brasileiro e destacam a importância da participação das mulheres e de seus movimentos no alcance desse objetivo.

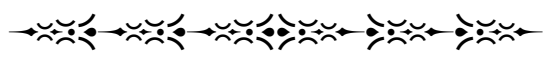

Andreza Nakano: Considerando seus percursos, como vocês veem o desenvolvimento da questão do parto na trajetória da saúde pública? E como participaram dessa trajetória?

Marcos Dias: Eu me lembro da crise das maternidades, no final dos anos 1980, antes de começar o processo de municipalização, quando a mortalidade materna era um absurdo, não havia vagas nas maternidades e a mídia dava notícias ruins sobre a assistência ao parto.

Maria do Carmo Leal: Tempo muito difícil!

Marcos Dias: Até que tem início um movimento na Secretaria Municipal de Saúde do Rio de Janeiro, no qual a equipe gestora tenta construir um modelo de assistência ao parto e ao nascimento para reverter aquele caos. Era uma história de muita violência, de peregrinação, de morte. Houve caso em que a mulher morreu no ônibus, indo para a maternidade. Essas histórias foram muito mobilizadoras, e isso marcou. Havíamos chegado ao fundo do poço, e foi então que esse movimento político começou a se organizar, com a perspectiva de fazer urgentemente alguma coisa por essas mulheres.

Maria do Carmo Leal: E aí começa também o nosso encontro - o Marcos e eu -, porque alguns dos que hoje fazem parte do nosso grupo de pesquisa na Escola Nacional de Saúde Pública (Ensp) naquela época estavam trabalhando no nível central da Secretaria Municipal de Saúde do Rio de Janeiro (SMSRJ). Hoje estamos todos juntos. Eu já trabalhava na Ensp, na área de epidemiologia da atenção à saúde da criança. Na verdade, o parto não era minha 
área de atuação, era a atenção à criança, mortalidade infantil. Comecei com os estudos de implantação do "Programa ampliado de imunização" (PAI). Depois passei a estudar mortalidade infantil e participei de um projetoda Financiadora de Estudos e Projetos (Finep) sobre a mortalidade infantil no município e na região metropolitana do Rio de Janeiro, em 1986. Por causa desse projeto, começamos uma relação com a SMSRJ. Quando a SMSRJ iniciou aquele programa tão importante, no início dos anos 1990, para modificar a forma de atender ao parto, convidaram-nas para também fazer estudos nessa área. Em 1996, fizemos outro estudo, financiado por ela, sobre a morbimortalidade perinatal. E assim fomos nos aproximando da questão do parto. Eu me lembro como a SMSRJ era atacada na televisão e nos jornais todo dia, por causa dos resultados muito ruins. A mulher chegava, o médico não atendia, e ela morria caminhando para a maternidade... era uma coisa horrível!

\section{Luiz Antônio Teixeira: Vocês estão falando do período pré-SUS ou pós-SUS?}

Marcos Dias: Do período em que se iniciava a implantação do SUS. Depois de 1988, com certeza. A Maternidade Leila Diniz (a primeira criada segundo o novo modelo de atenção ao parto e ao nascimento proposto pela SMSRJ) foi fundada em 1994, mas em 1990 havia somente a maternidade do Hospital Raphael de Paula Souza, ligado ao Ministério da Saúde (MS). Na crise que o Rio então vivia, a AP4 (Área Programática 4, que recobre os bairros de Jacarepaguá e Barra da Tijuca), que crescia aceleradamente, não tinha uma maternidade. Grande parte dos escândalos provinha das mulheres dessa área que peregrinavam para vir para o Miguel Couto ou que atravessavam a cidade para ir parir nas maternidades da Zona Oeste. É inaugurada, então, em 1990, a maternidade do Raphael de Paula Souza. Mas quando o presidente Collor assume ocorre uma crise enorme do serviço público, com muitas demissões etc. No âmbito municipal as coisas só pioravam. Não havia anestesistas, faltavam recursos humanos, era um desinvestimento completo.

No início dos anos 1990, com o processo de municipalização, a SMSRJ assume a gestão das maternidades da cidade e começa a fazer uma obra na maternidade do Raphael de Paula Souza. Então começa a se desenhar esse projeto de um modelo diferente de parto e nascimento, no planejamento da Maternidade Leila Diniz. A ideia era ter um acompanhante, ter uma banheira no pré-parto, começar a fazer uma maternidade que tivesse um modelo diferente. A conjuntura política da época era interessante, porque o secretário municipal de saúde era o Gazola. ${ }^{1}$

Maria do Carmo Leal: Ele era espiritualista. O nascimento tinha um sentido para ele.

Marcos Dias: Ele apoiou essa iniciativa. Era uma pessoa bacana, comprava a ideia e a defendia politicamente. E realmente víamos que não havia uma interferência política na administração das maternidades, uma coisa que atualmente é corrente, não é? Então, quando a secretaria faz o projeto da Maternidade Leila Diniz, já é incluída a presença do acompanhante, da banheira de pré-parto. Tudo isso inspirado numa experiência de Niterói no começo dos anos 1980. Lá havia uma casa de parto, e o grupo que a coordenava - que era da Saúde da Mulher - veio para a SMSRJ. 
Maria do Carmo Leal: Em Niterói, na gestão do Tomassini, ${ }^{2}$ houve uma revolução na atenção básica, inspirada na experiência de Cuba, que prestou assessoria à Secretaria de Saúde de Niterói.

Marcos Dias: Era um grupo de mulheres, feministas, e houve essa experiência de uma iniciativa privada, de uma casa de parto que, na verdade, era uma miniclínica, mas com a perspectiva de manter o parto fisiológico, normal. Esse grupo vem posteriormente para a prefeitura do Rio de Janeiro, e aí a equipe se agiganta, dado o potencial da cidade. E durante o planejamento da Leila Diniz, na costura política que começa a ser feita em torno dela, começam a surgir as ideias: vamos fazer lei do acompanhante... e começam a ser feitas todas essas movimentações.

Maria do Carmo Leal: E o movimento pela humanização da atenção ao parto, liderado pela Daphne, ${ }^{3}$ começa a ocorrer em âmbito nacional.

Marcos Dias: Na ocasião, em 1996, eu fui convidado para dirigir a Leila Diniz. Era para mim uma experiência muito diferente. Sou um obstetra que nasci e cresci igual a todos os meus coleguinhas (risos), virei rebelde depois. Até então eu era um obstetra com a formação mais tradicional possível, embora minha escola seja uma escola mais vaginalista, porque a Uerj (Universidade do Estado do Rio de Janeiro) tinha essa tradição de ser uma escola de parto normal, de formação para o fórceps. E quando eu chego na Leila Diniz me deparo com uma negociação assim: “Oh, você vai ter que frequentar uns espaços de ambientação, entendeu? O 'Espaço mulher'”. ${ }^{4}$ Havia também um movimento para incorporar certas experiências de prática humanizada que existiam no setor privado. A Fadynha, ${ }^{5}$ que era uma doula, e que atuava havia 30 anos no Rio de Janeiro, tinha um curso de gestante. Era uma coisa que se aproximava de uma promoção do parto normal, da valorização da mulher, da fisiologia.

Maria do Carmo Leal: Havia várias mulheres, todas feministas.

Marcos Dias: Sim, feministas históricas, pessoas que têm uma história na construção da saúde sexual e reprodutiva, na questão da assistência ao parto. Essas pessoas começam a trabalhar por volta de 1985, no Paism (Programa de Atenção Integral à Saúde da Mulher), no ano que é lançadoo documento da OMS que marca a fisiologia do parto. ${ }^{6}$

Maria do Carmo Leal: E ninguém fazia medicina baseada em evidência...

Marcos Dias: Esse documento foi fundamental para o movimento de reestruturação da assistência ao parto no Brasil.

Claudia Bonan: Entre o final dos anos 1980 e início dos 1990, no Brasil, em relação à assistência ao parto - mas também à saúde em geral -, desponta a questão dos direitos. Pelo que vocês contam, o parto vai ganhando força na agenda da saúde pública, em razão de dois problemas: de um lado, o "deserto médico", a falta e as deficiências da assistência - problemas que têm que ser enfrentados para garantir o direito à saúde reprodutiva; por outro lado, os questionamentos às práticas de assistência em si, com denúncia de intervenções excessivas e uso por vezes desnecessário e abusivo de tecnologias. Nesse momento histórico confluem, aparentemente, dois movimentos críticos. Como vocês veem isso? 
Maria do Carmo Leal: É quando a sociedade civil começa a se organizar. Em 1984 ocorre a abertura política, e então os movimentos das mulheres, assim como outros movimentos da sociedade, que haviam sido reprimidos, começam a se estruturar, a preparar a nova constituição, que veio pouco depois.

Marcos Dias: Eu vejo dessa forma: existe a vontade de construir um sistema que dê conta da demanda, e que possibilite reconhecer o melhor caminho para as gestantes se organizarem nessa rede de assistência. Mas há também o desejo de que, nessa construção, o modelo seja modificado. Então caminham juntas as ideias de garantir a assistência e de garantir uma assistência de melhor qualidade. Nessa época a taxa de cesárea já era alta. Tínhamos a maior taxa de cesárea no mundo, e continuamos crescendo, crescendo.

Maria do Carmo Leal: Já era de trinta e poucos por cento...

Marcos Dias: Sim, era de trinta e poucos por cento e já era uma taxa considerada absurda para a época. Quando eu era o diretor da Leila Diniz, nas reuniões dos diretores da maternidade, os outros diziam: "O Marcos vai falar o que ele está fazendo (risos). Ele é o cara que faz o que a secretaria quer que aconteça". Parecia que eu era o queridinho da SMSRJ, uma vez que era quem defendia a mudança de modelo que a secretaria preconizava. Então, nas reuniões, eu não era como os outros, ouvindo os planos da SMSRJ, eu era a pessoa que explicava os planos e como iriam ser implementados. Era bastante complicado porque, como podem imaginar, todos os outros diretores me olhavam pensando: "Ele é um vendido" (risos).

Maria do Carmo Leal: O porta-voz das mulheres.

Marcos Dias: Era bastante complexa a situação. Eu me lembro que, em 1994, quando abriu a Leila Diniz e começou o movimento de incluir as enfermeiras - numa segunda experiência, porque o Fernando Magalhães ${ }^{7}$ já tinha tido essa experiência - havia enfermeiras trabalhando na assistência ao parto de baixo risco, mas no modelo médico americano de cuidado. E a proposta na Leila Diniz era uma coisa diferente, eram as enfermeiras sendo introduzidas para atender no seu modelo, o modelo baseado em evidências, que respeitava a fisiologia, humanizado... mas aí começa o choque com os médicos.

Vocês imaginam isso 20 anos atrás? E havia ainda o conflito da responsabilidade pelo resultado. Mesmo no serviço para o qual havia uma proposta diferenciada, a enfermeira estava fazendo o parto e o médico chegava e dizia: vou fazer episiotomia, vou colocar um soro. Então, dependendo do plantão, havia toda essa briga. O Conselho Regional de Medicina (CRM) começa a produzir suas resoluções e estabelece que o chefe do plantão é o responsável pelo resultado. Isso reforçava o papel de resistência dos profissionais médicos, porque eles estavam ali, e o CRM dizia claramente: "Se uma enfermeira cometer um erro, quem vai pagar é você". Portanto, a lógica era reforçar essa divisão: "Já que a responsabilidade é minha, quem vai decidir o tipo de cuidado serei eu". Isso se repetia bastante. O CRM ia na Leila Diniz, fazia visita, escutava as queixas dos doutores. Os doutores mandavam carta para o CRM: "O diretor da maternidade obriga a gente a fazer ou não fazer isto ou aquilo". 
Maria do Carmo Leal: "O diretor da Leila Diniz deixa a enfermeira fazer o parto como ela quer...".

Marcos Dias: O conflito ocorria nesse nível. Houve uma grande cisão, porque num plantão a equipe de enfermagem - isso foi uma crise - denunciou um médico na delegacia. Então eu falei: "Não posso mais esticar essa corda a ponto de perder, depois, o controle sobre os médicos, ou ser identificado com as práticas desses sujeitos. Era 'ou eu ou eles'”. Foi muito estressante, mas os médicos saíram, foram para outra maternidade, e nós retomamos o projeto com as mesmas propostas, mas sem tanto conflito, pois em determinado momento a posição da pessoa fazia diferença no que estava acontecendo no processo. Não se pode bater de frente quando se está construindo uma coisa que era...

Maria do Carmo Leal: Uma contraproposta, não é?

Marcos Dias: Num movimento que era extremamente dividido. Porque as próprias auxiliares de enfermagem olhavam para a questão da humanização do parto com certa desconfiança: "Quando eu pari ninguém ficou me dando a mãozinha, ninguém ficou passando paninho". "Eu não passei por isso, por que é preciso esse nhém nhém nhém todo?"

Nesse contexto, muitas coisas foram acontecendo simultaneamente. A prefeitura começou a fazer aqueles seminários de obstetrícia baseada em evidências. Eu me lembro de um deles, para o qual chamamos pessoas de fora, que tinham alguma experiência; então o Sophia Feldman ${ }^{8}$ começou a se incorporar a esse grupo, eles vieram falar da sua experiência com enfermagem assistindo o parto. Nisso já estamos em 1998. Nesses seminários os médicos começaram a ouvir coisas diferentes.

Maria do Carmo Leal: Hoje eu estava olhando os dados da pesquisa "Nascer no Brasil" (Inquérito nacional sobre parto e nascimento) ${ }^{9}$ - porque estou fazendo um artigo -, e a taxa de cesariana anteparto é baixa no Sudeste, quando comparada à do restante do Brasil. Isso é fruto desse trabalho. Na verdade, no SUS, o Sudeste se destaca positivamente em relação à cesariana anteparto. Isso tem a ver com esses esforços que surgiram aqui no Rio, em Belo Horizonte e em São Paulo também. Hoje é possível ver o resultado de um movimento histórico na estatística do parto. Porque o Sudeste é diferente de todas as outras regiões, tem uma situação bem melhor.

Marcos Dias: E foi um movimento que lançou novas questões: "Se vamos introduzir as enfermeiras na assistência ao parto, como vamos formá-las? Quem vai formá-las?". É quando se decide criar a Casa de Parto David Capistrano. Em 1998, o José Serra, que era ministro da Saúde, designa o sanitarista David Capistrano ${ }^{10}$ para gerenciar alguns projetos. O David Capistrano se apaixona então pela maternidade e diz: "Vou fazer uma casa de parto no Rio de Janeiro".

Maria do Carmo Leal: Que recebe o nome dele.

Marcos Dias: Nesse momento começa o processo de construção da casa de parto e de capacitação da enfermagem, numa associação entre a Uerj e a SMSRJ. Capacitação da enfermagem para o pré-natal, para assistência ao parto, pois até então não havia a atuação de um grande número de enfermeiras. 
Maria do Carmo Leal: Houve aquele programa da Jica (Japan International Cooperation Agency $)^{11}$ que teve muita importância na formação dessas enfermeiras. As daqui do Rio também, não é? Todas formadas no Japão.

Marcos Dias: Sim. Foram para o Japão.

Maria do Carmo Leal: Porque era quem abria campo de formação. A Inglaterra não estava nem aí, era o Japão.

Marcos Dias: Na verdade, a Jica fazia uma ponte entre os movimentos, via o que estava acontecendo no Rio e nos convidava para trabalhar com eles nas maternidades do Ceará, na promoção do parto humanizado. Começou então um movimento assim: íamos para o Ceará, fazíamos palestras nas maternidades, explicávamos o que estava acontecendo, como é o parto pela enfermagem. Isso porque no Ceará houve a atuação do Galba de Araújo, que era muito importante, pois tinha estruturado uma rede de assistência ao parto por parteiras. ${ }^{12}$ E a Jica começa a valorizar essa história.

Maria do Carmo Leal: Principalmente em partos domiciliares, em pequenas unidades, no interior, na área rural, onde não havia médico. Onde não havia nada. Não havia competição com o hospital.

Claudia Bonan: Vou voltar a uma coisa que me inquieta muito. Com a Constituição de 1988 se consagra o direito universal à saúde. Nos anos 1990, o SUS começa a ser construído, os serviços de saúde se reestruturam, e dezenas de milhões de brasileiros são incorporados ao sistema de saúde. Durante essas décadas trabalhamos para dar concretude àqueles princípios e diretrizes que fundamentam o SUS e, ainda hoje, em várias áreas, nos deparamos com o problema da qualidade.

Maria do Carmo Leal: Até hoje!

Claudia Bonan: Até hoje. A hospitalização do parto e a escalada de cesarianas antecede a universalização do acesso à saúde, ou seja, já começa nos anos 1970. A partir dos anos 1990, quando as mulheres são incorporadas maciçamente ao sistema de saúde, parece que se instala uma situação paradoxal: o lado positivo é o maior acesso aos serviços de saúde, mas, ao mesmo tempo, parece que são mais submetidas àquilo que temos discutido com a designação de violência obstétrica: o parto em solidão, longe da família, maus-tratos verbais, episiotomias rotineiras e outras intervenções que não necessariamente trazem benefícios e, ao contrário, podem tornar o parto uma experiência desagradável, mais doloroso...

Maria do Carmo Leal: Tragédias.

Claudia Bonan: Vendo esse período da história então, tem-se essa impressão dos efeitos paradoxais da ampliação do acesso aos serviços de saúde...

Marcos Dias: As estatísticas não estavam mudando. Eu me lembro muito claramente de chegar para Diana Valladares ${ }^{13} \mathrm{um}$ dia e falar assim: "Diana, porque que a taxa de cesariana não está caindo?". Ela falou: "Não vamos falar sobre isso agora". Porque eu acho que ela teve uma visão clara de que era um trabalho de muito longo prazo, que não se tratava 
simplesmente de colocar as enfermeiras na assistência e, imediatamente, conseguir mudar o modelo e os resultados. Não é nada disso, é um processo arrastadíssimo. E nessa época, sem a conscientização das mulheres sobre a sua autonomia, o seu direito ao corpo, ao seu parto, ao seu protagonismo... esses simplesmente não eram temas que fossem mencionados.

Andreza Nakano: Era invisível...

Marcos Dias: Era totalmente invisível. Nessa época começamos a fazer as estatísticas não só de cesárea, mas de taxa de episiotomia. Imagina! Ninguém nunca havia acompanhado episiotomias. Era um procedimento para ser feito, então não era problema. Problema talvez fosse fazer pouca episiotomia. Então, na Leila Diniz, começa a ser feita a discussão sobre episiotomias, o controle do uso da ocitocina. Eu lembro que publicamos, acho que foi em 1998, no Saúde em Foco, da Prefeitura, os dados da Leila Diniz, que mostravam resultados positivos de mudança das práticas de assistência ao parto.

Maria do Carmo Leal: Eu me lembro disso.

Marcos Dias: Havia o caso dos resultados da Leila Diniz, onde implantamos umas fichinhas que os doutores tinham que preencher, respondendo: vai fazer a amniotomia? Qual a indicação da amniotomia? Vai aplicar ocitocina? Qual é a indicação da ocitocina? Vai utilizar? Fez episiotomia? Qual é a indicação? Um pouco para obrigar os médicos a pensar o que justificava aquela intervenção. Que eles claramente nem viam como intervenção, viam como o cuidado a ser feito. Daí a importância daquele manual de assistência ao parto, que foi traduzido (OMS, 1996). Porque ele virou a "bíblia" da ReHuNa (Rede pela Humanização do Parto e Nascimento) ${ }_{1}^{14}$ de quem trabalhava com essa questão da mudança de modelo; era uma referência bibliográfica para esse grupo, no qual se misturavam médicos, sanitaristas e outros.

Maria do Carmo Leal: Feministas.

Marcos Dias: Feministas, antropólogos, o pessoal da epidemiologia. Todos olhando para o problema. E os encontros começam a acontecer. Acho que os encontros vão se somando assim, progressivamente, de maneira a mostrar que estávamos diante de um grande desafio, de saber como fazer para mudar.

Maria do Carmo Leal: Uma das coisas que você estava comentando, e que eu tenho dúvida, é se esse "pacote de maldades" que se faz com a mulher no parto, que vem devagarzinho melhorando, não tem um componente de gênero. O sistema de saúde maltrata todo mundo, maltrata o idoso, a criança. Mas eu acho que em particular o absurdo que acontecia no parto era uma coisa nunca vista, o que se gritava com a mulher, o que se xingava a mulher...

Marcos Dias: Batia...

Maria do Carmo Leal: O que se batia e o que se dizia: "Na hora de fazer gostou e agora está reclamando de quê?". Isso era um absurdo e eu nunca vi isso [acontecer] com os outros. $\mathrm{Eu}$ acho que esses maus-tratos com a mulher que ocorrem aqui no Brasil - e ocorriam mais ainda, mas ainda ocorrem bastante - têm algo de discriminação contra a mulher, 
esse machismo tremendo dessa sociedade que bate na mulher na hora que ela vai parir o fruto de uma relação sexual. A coisa da sexualização do parto. Uma coisa impressionante!

O projeto "Nascer no Brasil" foi fruto de um desses encontros. Você estava junto (referindo-se a Marcos Dias). Fui eu, você, Bebeth ${ }^{15}$ e a Suzanne Serruya, na época, diretora do Decit (Departamento de Ciência e Tecnologia do Ministério da Saúde), não me lembro quem mais estava. Foi num encontro nacional de perinatologia - que a Bebeth organizava, para qual fomos convidados para apresentar resultados de pesquisa -, que conversamos com Suzanne Serruya sobre a necessidade de estudar o problema da cesariana no Brasil.

Esse encontro foi em 2007 e dele saiu, em 2008, um edital CNPq/Decit convocando pesquisadores para apresentar projetos sobre a cesariana desnecessária. Na conversa com a Serruya, lembro-me de ter dito: "Não é mais possível aceitarmos uma coisa como essa que vem acontecendo, esse nível de cesariana que só cresce. Deve ser por isso que a mortalidade materna não baixa". Naquela época ninguém tinha prova disso, agora temos alguns resultados analisados com os dados do "Nascer no Brasil" que mostram essa associação.

Marcos Dias: Um ano antes nós tínhamos feito um estudo para a Agência Nacional de Saúde Suplementar (ANS).

\section{Andreza Nakano: Sobre cesáreas?}

Maria do Carmo Leal: Exatamente, fazendo uma revisão sistemática da literatura científica sobre todos os mecanismos utilizados para a redução de cesárea, o que dava certo, o que não dava, os resultados alcançados nos estudos.

Marcos Dias: Depois da revisão sistemática fizemos uma pesquisa de campo em duas maternidades privadas, entrevistando as mulheres.

Maria do Carmo Leal: Aí amadurecemos a ideia de que precisávamos fazer algo maior pelo Brasil.

\section{Luiz Antônio Teixeira: Onde foi localizado esse estudo?}

Marcos Dias: Fizemos no Rio, em 2000, e foi publicado pela ANS e financiado pela ANS/MS.

Maria do Carmo Leal: O Marcos e a Rosa ${ }^{16}$ assumiram a frente, estávamos junto, estudando, pela primeira vez, o que estava acontecendo no setor privado. Esse projeto foi muito importante para nossa luta pela melhoria da atenção ao parto. Claro que não foi o projeto sozinho, são muitas pessoas trabalhando nessa direção. Como o ministério, num esforço enorme, com muitas dificuldades, mas com persistência, principalmente depois da entrada da Esther. ${ }^{17}$ Quando a Esther entrou, a área da Saúde da Mulher já tinha sido dirigida pela Daphne e por outras mulheres combativas.

Marcos Dias: Foi uma feliz coincidência o que aconteceu no Ministério da Saúde, com a Tânia Lago ${ }^{18}$ e o Serra. ${ }^{19}$ Depois entra a Maria José, ${ }^{20}$ que não é exatamente uma portabandeira da questão da maternidade, por conta da questão do feminismo, mas entende... $\mathrm{E}$ viajamos muito, eu e Maria José, para aqueles seminários de assistência neonatal e obstétrica, humanizada, baseada em evidência científica. Viajávamos o Brasil inteiro. Depois da Maria 
José houve outros nomes. Eu sei que havia um grupo que gerenciava continuamente a saúde da mulher, com o qual tínhamos muita interlocução.

Maria do Carmo Leal: Começa também a existir financiamento.

Marcos Dias: Desde 2000, quando fizemos o primeiro Seminário Internacional de Humanização do Parto, no Ceará. Desde antes já conseguíamos ter interlocução com o ministério. Existe o PHPN (Programa de Humanização do Parto e Nascimento), implementado pela Tânia Lago, Suzanne Serruya e Ana Cristina Tanaka. ${ }^{21}$

Marcos Dias: Então a ReHuNa começa a ter uma interlocução muito grande. Isso coincide com o movimento político no Rio, com o movimento no ministério. Existe certa estruturação, surge o manual do ministério para a assistência ao parto humanizado, começa-se a produzir documentos, fazer seminários, campanhas... as coisas caminham paralelamente em mais de um nível da política, e isso faz toda a diferença. Eu acho que essa história da trajetória do ministério é muito importante, até mesmo para esse caminho que levou até a Rede Cegonha. ${ }^{22}$

Maria do Carmo Leal: Muito importante. E essa organização das mulheres também, não é? Começam a existir grupos organizados para o parto em vários lugares e acho que isso também foi importante.

Marcos Dias: A minha convicção é de que o que fez toda a diferença foram as mulheres.

Maria do Carmo Leal: Eu também acho.

Marcos Dias: O mais forte nessa transformação é que as mulheres passaram a colocar o problema do parto no Facebook, na mídia eletrônica, e aí começaram a surgir os blogs sobre parto.

Maria do Carmo Leal: É, havia vários grupos em São Paulo e no Rio de Janeiro também.

Marcos Dias: Havia vários grupos, e isso deu capilaridade e ampliou a percepção das mulheres. Elas começam a ter voz sobre essa coisa perversa: os maus-tratos no serviço público, a violência, o Kristeller, ${ }^{23}$ a morte dos bebês. Todas essas coisas começam a ter uma reverberação enorme depois que esses grupos começam a trabalhar mais efetivamente. Acho que conseguimos traduzir isso em alguns dos artigos dos nossos estudos. Naquele artigo sobre a escolha do tipo de parto já apontávamos isso: as mulheres não querem a cesárea, porém são orientadas a fazê-la (Domingues et al., 2014).

Maria do Carmo Leal: Acho que a participação das mulheres, que o Marcos mencionou, ocorreu em governos que tinham algum interesse em melhorar a saúde. Tinham compromisso. Mesmo na época do Serra, no governo Fernando Henrique Cardoso, eles davam espaço para levar adiante uma melhoria da atenção à saúde das mulheres, de um modo geral. E nessa sucessão de governos surgem pessoas interessantes que vão, cada vez mais, recortando melhor o problema, ampliando a capilaridade da discussão dentro SUS. Era uma coisa que até então não existia.

Marcos Dias: Ocorria em vários níveis. 
Maria do Carmo Leal: Havia um conjunto de representantes desenvolvendo esse trabalho de melhoria de atenção ao parto dentro do sistema estadual e municipal. Dessa forma, esse movimento começa a ter uma capilaridade enorme dentro do sistema público de saúde. E, mais recentemente, dentro do sistema privado começa a acontecer um fenômeno, também provocado pelas mulheres organizadas, que é impressionante. O setor privado é uma área sempre muito difícil, porque tem mais de $90 \%$ de cesariana. Em São Paulo, entraram com um processo na procuradoria estadual contra a ANS (Agência Nacional de Saúde Suplementar), porque a ANS era conivente com as taxas de cesáreas. Eram as pessoas desse movimento das mulheres pelo parto normal, não sei qual grupo, ou se foi o conjunto deles. Um procurador de São Paulo aceitou, achou que aquilo tinha sentido. Antes disso as mulheres me pediram e eu enviei 150 números da revista que nós publicamos, sobre o "Nascer no Brasil", nos Cadernos de Saúde Pública, para distribuir aos procuradores de São Paulo. ${ }^{24}$ Nessa revista era apresentada uma revisão do que era o bom parto. Até então, quando chegava um processo, os procuradores recorriam ao Rezende $^{25}$ para buscar informação. O procurador aceitou o processo, achou que era justa aquela afirmação de que as mulheres estavam sendo ludibriadas, que era possível a ANS regular, fazer aquilo que foi criada para fazer. As mulheres pediam para o setor privado implantar uma caderneta da gestante, para que, no caso de quererem mudar de médico, elas pudessem levar os primeiros exames e continuar o processo com outro médico. A segunda coisa que pediam era a obrigação de uso do partograma. ${ }^{26}$ Também queriam que a ANS abrisse o acesso à informação sobre a taxa de cesárea dos médicos, das operadoras e dos hospitais, para as mulheres consultarem se tivessem dúvidas sobre o médico que as estava acompanhando.

A ANS teve que responder, concordando e implementando as solicitações requeridas pelas mulheres nesse processo. Como nada acontece por acaso, naquele momento a Jacqueline ${ }^{27}$ estava voltando para a ANS, após defender a tese que tinha feito sobre cesariana no setor privado. Ela ficou responsável por essa questão. Em consequência desse processo, mas, também em continuidade aos esforços anteriores, malsucedidos, da ANS em reduzir cesarianas, a agência resolveu fazer uma chamada para os hospitais privados participarem de um projeto para redução de cesarianas. Eles usaram como estratégia a parceria que já vinham desenvolvendo com um instituto norte-americano, o Institute of Health Care Improvement (IHI). O IHI trabalhava com a instalação de protocolos e qualificação dos hospitais para que recebam um selo de qualidade na atenção hospitalar. Para esse projeto de melhoria da atenção ao parto, chamado "Parto adequado", ${ }^{28}$ a ANS também convidou, como parceiro, o Einstein (Hospital Albert Einstein, SP), que é um hospital muito reconhecido. Houve uma convocação de hospitais privados de grande prestígio no país, que foram convidados a participar desse projeto-piloto. Durante um ano e meio os hospitais estiveram juntos em um processo de aprendizagem e mudança de modelo de atenção ao parto e nascimento, o que constituiu um trabalho interessante, que agora nós estamos avaliando ("Projeto nascer saudável"). Isso resultou em $14 \%$ de redução no número de cesáreas. Eles trabalharam não com toda a clientela do hospital, mas com um grupo-piloto de mulheres com algumas características. Mas o que importa é que haja impacto no hospital como um todo, e a taxa de cesárea desses hospitais baixou, em média, 14\%. Agora essa experiência foi expandida 
para 150 hospitais. Então também tem algo acontecendo no setor privado e isso é fruto novamente do empenho das mulheres.

Claudia Nakano: E no setor público, como vocês veem? Apesar de 20 anos de iniciativas interessantes, governamentais e não governamentais, as dificuldades tanto para a redução das cesarianas, como para a transformação do modelo persistem. Como esses processos políticos vão culminar na Rede Cegonha?

Marcos Dias: Em 2010, na campanha da Dilma ${ }^{29}$ para a Presidência, ela vem ao Rio e vê a experiência da Cegonha Carioca, que é a experiência de buscar a gestante em casa.

Maria do Carmo Leal: De buscar a gestante em casa para resolver aquele crônico problema da peregrinação de gestante buscando vaga para parir, que havia no município do Rio de Janeiro e que foi solucionado.

Marcos Dias: É, tinha a experiência da Cegonha Carioca, que inspirou o nome da Rede Cegonha, que foi assumida pela Dilma. Ela toma posse em $1^{\circ}$ de janeiro, e em março lança a Rede Cegonha, que era uma rede de cuidados para as mulheres. Foi uma política que marcou. Uma política para as mulheres, para os bebês e com nove bilhões de reais em recursos.

Maria do Carmo Leal: Reservados.

Marcos Dias: Recursos reservados para essa iniciativa. Então muda a metodologia, porque, como a Maria do Carmo Leal mencionou, a experiência do ministério era fazer treinamento, elaborar material instrucional, mas dependendo do gestor local. Antes da Rede Cegonha, no final do segundo governo Lula, ${ }^{30}$ o governo passa a apostar numa experiência que se chamava PQM. ${ }^{31}$ Era a experiência de qualificação das maternidades do Norte e do Nordeste, porque, apesar da melhora geral dos indicadores do Brasil, essas regiões ainda tinham enorme diferencial na mortalidade infantil e materna. Aqueles lugares não atingiam as metas do milênio. ${ }^{32}$ Então, ocorreu essa qualificação das maternidades, baseada nos apoiadores dos serviços, ${ }^{33}$ nesses lugares, para mudar a prática, mudar as rotinas, o processo de trabalho. Quando é lançada a Rede Cegonha, a Área Técnica de Saúde da Mulher do Ministério da Saúde traz essa experiência do PQM. Começa aí a estruturação da Rede Cegonha, com um gigantesco esforço administrativo: recrutar e treinar os apoiadores dos serviços, fazer projetos com as maternidades para implementação de boas práticas, projetos com os gestores locais municipais e estaduais, projetos de residência em enfermagem obstétrica, gerir dinheiro...

Maria do Carmo Leal: Mudança de estrutura...

Marcos Dias: Foi uma maneira de formar 2.500 enfermeiras, financiar cursos de enfermagem obstétrica.

Maria do Carmo Leal: Um projeto nacional.

Marcos Dias: Esse é um projeto enorme, um projeto de governo. É uma política de governo composta por uma sucessão de iniciativas. É quando começa o acolhimento com classificação de risco, incorporado a essa proposta. A proposta do quarto PPP, ${ }^{34}$ do acompanhante... Eu acho que a Rede Cegonha começa a trazer para dentro do Ministério da Saúde a seguinte 
perspectiva: se você vai implantar uma mudança de processo dessa magnitude, tem que ter alguém do ministério - um apoiador institucional - gerenciando esse processo junto com o gestor local. E aí as coisas efetivamente começam a acontecer.

Maria do Carmo Leal: Uma presença física do programa.

Marcos Dias: Daí a postura dos diversos municípios de montar sua rede de assistência, de referência e contrarreferência, o acolhimento com classificação de risco, os projetos para centros de parto normal, uma quantidade de coisas que foram sendo feitas nesse período da Rede Cegonha. O ministério publica uma série de resoluções que envolvem todas essas questões.

Maria do Carmo Leal: E também os protocolos clínicos começam a ser implantados na rede, uma medicina baseada em evidência científica. Realmente é uma mudança bem grande. No momento, estamos terminando a avaliação da Rede Cegonha, porque a primeira avaliação foi feita pelos próprios estados. Foi um problema, porque alguns estados não preencheram os formulários, não fizeram a avaliação de forma adequada. Para o segundo ciclo, Esther Vilela convidou a Fiocruz e a Universidade Federal do Maranhão, para, em parceria, fazer uma avaliação externa da Rede Cegonha. Foram 630 maternidades, uma pesquisa maior do que todas que já havíamos feito. Era para começar em 2015, mas a situação política impediu e somente agora, em 2017, esse estudo se completou.

Marcos Dias: A avaliação é feita em cima dos princípios que constituíram o ideário da Rede Cegonha: respeito à mulher, diminuição da violência, presença do acompanhante, diminuição das intervenções desnecessárias no parto normal. E, no setor privado, há iniciativas como o "Parto adequado". Agora é possível encontrar alguns hospitais de operadoras nos quais se fazem coisas muito interessantes. Ao mesmo tempo, existem outros nos quais não se deu um passo, de forma que no final, suponho que alguma coisa melhorou. O número de episiotomias tenho certeza que baixou. Então acho que teremos alguns ganhos com o esforço desses anos.

Claudia Bonan: Estamos em meados de 2017, diante de uma enorme crise política e institucional, que começa com a derrubada da legítima presidenta do Brasil, Dilma Rousseff, e a instalação de um governo impopular e retrógrado no que diz respeito aos direitos. Quais os cenários possíveis para o futuro dessas políticas? Daqui para frente quais são as novas fronteiras, quais as armas que vamos utilizar? Se a ruptura democrática não tivesse acontecido, estaríamos discutindo o futuro de outra maneira. Como é que vocês estão vendo, a partir do cenário atual, o futuro das políticas de atenção ao parto?

Maria do Carmo Leal: Eu acho que é um caminho sem volta. Não sei o que você pensa, Marcos, pode ser que seja um exagero de otimismo, que até não me frequenta muito nesses tempos atuais, mas acho que essa questão do parto vai entrar numa rota de modificação. Não sei aonde vamos chegar, se vamos chegar perto do que gostaríamos, mas vai melhorar. Essa é a minha impressão. Eu acho que essas questões passaram a fazer parte do interesse da classe média. 
Marcos Dias: Foram as próprias mulheres em rede que criaram a sua própria mídia.

Maria do Carmo Leal: Exato. Elas foram compreendendo que o que estava se fazendo cada vez mais não era bom para elas. Hoje vejo que minhas filhas, as amigas da minha filha, estão mudando, então acho que é uma coisa que vai se colocar muito melhor na classe média e, dessa forma, vai influenciar de modo geral. Já no sistema público, o número de cesáreas não é tão grande como no privado - embora seja muito alto -, e eu acho que isso também vai influenciar. As mulheres, mesmo as que frequentam o setor público, também estão mais informadas, interagem com a internet, com tudo isso. É outro tempo.

Andreza Nakano: Um dos objetivos principais da nossa entrevista foi analisar esse processo de criação de políticas para o parto e seus impactos na sociedade. Acho que vocês traçaram muito bem essa trajetória.

Maria do Carmo Leal: É, e a mulher joga num lugar especial aí. Com certeza essa reflexão tem como centro as mulheres.

Entrevistadores: Muito obrigado pela participação de vocês.

\section{NOTAS}

${ }^{1}$ O médico Ronaldo Gazolla foi secretário municipal de Saúde do RJ entre 1992 e 2000.

${ }^{2}$ Hugo C.B. Tomassini era professor na Universidade Federal Fluminense e assumiu a Secretaria de Saúde do Município de Niterói em 1977.

${ }^{3}$ A médica Daphne Rattner foi uma das fundadoras e presidente da Rede pela Humanização do Parto e Nascimento (ReHuNa) e integrante das comissões de especialistas do Ministério da Saúde sobre a Rede Cegonha e o Parto Normal.

${ }^{4} \mathrm{O}$ Espaço Mulher foi um Centro de Treinamento em Atenção Integral à Saúde da Mulher, criado nos anos 1990 por profissionais de saúde que assumiram a Gerência do Programa da Mulher na SMSRJ.

${ }^{5}$ Maria de Lourdes da Silva Teixeira, a Fadynha, foi fundadora e presidente da Associação Nacional de Doulas e trabalha com preparação de grupos de casais grávidos.

${ }^{6}$ Nos anos de 1980, a OMS realiza uma sequência de três conferências sobre uso apropriado de tecnologias no parto, e a de 1985 foi em Fortaleza (WHO, 1985). Nesse movimento, nos anos de 1990, são publicados manuais pela OMS e pelo Ministério da Saúde.

${ }^{7}$ Fernando Magalhães (1878-1944) foi médico e diretor da cadeira de ginecologia e obstetrícia da Faculdade Nacional de Medicina da Universidade do Brasil. É considerado o "pai da obstetrícia brasileira" (Martins, 2004).

${ }^{8}$ O Hospital Sophia Feldman é uma maternidade filantrópica fundada em 1982, em Belo Horizonte, que presta serviços para o SUS. Caracteriza-se por oferecer atenção humanizada ao parto $(<\mathrm{http}$ :/www. sofiafeldman.org.br/atenção-a-mulher/>).

${ }^{9}$ A partir de um edital de pesquisa de 2009, a pesquisadora Maria do Carmo Leal (Ensp/Fiocruz) coordenou o "Nascer no Brasil: inquérito nacional sobre parto e nascimento". Na página web da pesquisa podem ser localizadas, entre outros materiais, as publicações do estudo (<pesquisahttp://www6.ensp.fiocruz.br/ nascerbrasil/>).

${ }^{10}$ O médico sanitarista David Capistrano da Costa Filho foi uma importante liderança da área da saúde, que desenvolveu e implementou políticas públicas precursoras e inovadoras.

${ }^{11}$ A Agência Japonesa de Cooperação Internacional (Jica) promoveu a troca de experiências entre as parteiras japonesas e as enfermeiras obstétricas de países em desenvolvimento, visando contribuir com as iniciativas de qualificação da assistência obstétrica empreendidas pelo Ministério da Saúde brasileiro. 
12 O obstetra cearense José Galba de Araújo (1917-1985) trabalhou na implantação e dirigiu a Maternidade Escola Assis Chateaubriand no Ceará.

${ }^{13}$ A sanitarista Diana Valladares foi gerente do Programa de Saúde da Mulher na SMSRJ.

${ }^{14}$ A ReHuNaé uma organização da sociedade civil que, desde 1993, divulga a assistência e cuidados perinatais com base em evidências científicas, com vistas a diminuir as intervenções desnecessárias e promover a compreensão do parto como um processo natural e fisiológico.

${ }^{15}$ A médica Maria Elisabeth Lopes Moreira é especialista em perinatologia, pesquisadora no Instituto Fernandes Figueira/Fiocruz.

${ }^{16}$ A médica Rosa Domingues é pesquisadora no Instituto Evandro Chagas/Fiocruz.

${ }^{17}$ A obstetra Maria Esther de Albuquerque Vilela foi coordenadora da Área Técnica de Saúde da Mulher do Ministério da Saúde entre 2011 e 2017.

${ }^{18}$ A médica Tania di Giacomo do Lago foi coordenadora da Área Técnica de Saúde da Mulher do Ministério da Saúde entre 1995 e 2002.

${ }^{19}$ José Serra foi ministro da Saúde entre 1998 e 2002.

${ }^{20}$ A médica Maria José Oliveira de Araújo foi coordenadora da Área Técnica de Saúde da Mulher do Ministério da Saúde entre 2003 e 2006.

${ }^{21}$ A enfermeira Ana Cristina d'Andretta Tanaka é professora titular do Departamento de Saúde Maternoinfantil da Faculdade de Saúde Pública da Universidade de São Paulo, onde pesquisa saúde da mulher.

22 A Rede Cegonha é uma rede de cuidados lançada em 2011 pelo governo brasileiro. Uma estratégia inovadora do Ministério da Saúde que visa implementar uma rede de cuidados para assegurar às mulheres o direito ao planejamento reprodutivo e a atenção humanizada à gravidez, ao parto e ao puerpério e às crianças o direito ao nascimento seguro e ao crescimento e ao desenvolvimento saudáveis.

${ }^{23}$ A manobra de Kristeller é uma técnica obstétrica que consiste na aplicação de pressão na parte superior do útero com o objetivo de facilitar a saída do bebê. Hoje é considerada danosa à saúde e, ao mesmo tempo, ineficaz.

${ }^{24}$ Referindo-se a Domingues et al. (2014).

${ }^{25}$ Jorge Fonte de Rezende (1911-2006). Importante obstetra brasileiro, professor de obstetrícia e autor do manual de obstetrícia mais popular do país. Reconhecido por sua posição em favor da cesariana. Ver Nakano, Bonan, Teixeira (2016).

${ }^{26}$ Partograma é um gráfico onde são anotadas a progressão do trabalho de parto e as condições da mãe e do feto.

${ }^{27}$ A enfermeira Jacqueline Alves Torres é especialista em regulação de saúde suplementar da ANS. Para a tese, ver Torres (2014).

${ }^{28}$ O projeto "Parto adequado" é uma ação da ANS direcionada a hospitais com maternidades visando subsidiar mudanças na atenção ao parto, em especial a redução das cesarianas.

${ }^{29}$ Dilma Rousseff, então candidata nas eleições presidenciais em 2010, presidente do Brasil entre 2011 e 2016.

${ }^{30}$ Luiz Inácio Lula da Silva, presidente do Brasil entre 2003 e 2010.

31 Trata-se do Plano de Qualificação das Maternidades e Redes Perinatais da Amazônia Legal e Nordeste, uma iniciativa do Ministério da Saúde.

32 Os "Objetivos de desenvolvimento do milênio" incluíam a redução da mortalidade materna e infantil, estabelecendo metas específicas a serem alcançadas até o ano de 2015.

${ }^{33}$ O dispositivo do "apoio institucional" foi utilizado no PQM e depois na Rede Cegonha, sendo um arranjo técnico-político fundamental para implementação da Rede Cegonha. Ver Costa (2014).

${ }^{34}$ PPP é uma sigla que se refere a um aspecto da humanização do parto e do nascimento, que consiste na assistência à gestante no mesmo ambiente durante o pré-parto, o parto e o puerpério com a presença do acompanhante de sua escolha. 


\section{REFERÊNCIAS}

COSTA, Aline de $\mathrm{O}$.

Apoio institucional na Rede Cegonha: aposta nos espaços coletivos para sua implementação. Dissertação (Mestrado em Saúde da Criança e da Mulher) - Instituto Nacional de Saúde da Mulher, da Criança e do Adolescente Fernandes Figueira, Fiocruz, Rio de Janeiro. 2014.

DOMINGUES, Rosa Maria et al.

Processo de decisão pelo tipo de parto no Brasil: da preferência inicial das mulheres à via de parto final. Cadernos de Saúde Pública, v.30, supl., p.S101-S116. 2014.

MARTINS, Ana Paula Vosne.

Visões do feminino: a medicina da mulher nos séculos XIX e XX. Rio de Janeiro: Editora Fiocruz. 2004.

NAKANO, Andreza; BONAN, Claudia; TEIXEIRA, Luiz Antônio.

Cesárea, aperfeiçoando a técnica e normatizando a prática: uma análise do livro Obstetrícia, de Jorge de Rezende. História, Ciências, Saúde-Manguinhos, v.23, n.1, p.155172. 2016.
OMS.

Organização Mundial de Saúde. Assistência ao parto normal: um guia prático. Genebra: OMS. 1996.

TORRES, Jacqueline Alves.

Análise da contribuição de um programa perinatal multifacetado para a redução da prevalência de cesarianas em um hospital privado: um subprojeto da pesquisa "Nascer no Brasil". Tese (Doutorado em Epidemiologia em Saúde Pública) - Escola Nacional de Saúde Pública Sergio Arouca, Fiocruz, Rio de Janeiro. 2014.

WHO.

World Health Organization. Appropriate technology for birth. Lancet, v.24, n.2, p.436437. 1985. 